\title{
Chylothorax: eine seltene Komplikation nach Akupunktur
}

\begin{abstract}
Japanische Ärzte berichten über den Fall einer 37-jährigen Patientin, die zwei Tage nach einer Akupunkturbehandlung wegen Thoraschmerzen und Atemnot stationär aufgenommen wurde.
\end{abstract}

— Die Frau hatte sich wegen linksseitiger Rückenschmerzen in die Behandlung eines erfahrenen Akupunkteurs begeben. Dieser applizierte die Nadeln im Nacken und am oberen Rücken. Als die Patientin zwei Tage nach der Akupunktur mit Thoraxschmerzen und Kurzatmigkeit im Krankenhaus erschien, ergab die klinische Untersuchung ein abgeschwächtes Atemgeräusch links. Das Labor war unauffällig, aber das CT zeigte einen linksseitigen Pneumothorax. Daraufhin wurde eine

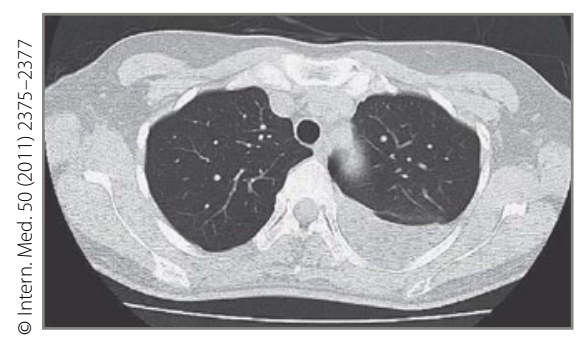

Pneumothorax im CT.

Drainage gelegt. Diese lieferte eine große Menge $(1,4 \mathrm{l})$ von Flüssigkeit, die reich an Chylomikronen war.

Die Autoren folgerten daraus, dass eine Akupunkturnadel den Ductus thoracicus penetriert haben musste. Die $\mathrm{Pa}$ tientin wurde konservativ versorgt und konnte am 12. Tag das Krankenhaus geheilt verlassen.

\section{Kommentar}

Ein Pneumothorax nach Akupunktur wurde schon öfter beschrieben, nicht jedoch ein akupunkturinduzierter Chylothorax. Da ein Chylothorax eine Mortalitätsrate von fast $50 \%$ aufweist, ist diese seltene Komplikation bedeutsam. Die Patientin hatte Akupunkturnadeln im Nacken und oberen Brustwirbelbereich gesetzt bekommen. Hier kann der Ductus thoracicus in der Reichweite einer Akupunkturnadel liegen. In den meisten Fällen von Chylothorax lässt sich keine Ursache auffinden. Die Autoren fragen sich daher, ob der Akupunktur hier nicht eine größere Bedeutung zukommen könnte, als bislang angenommen.

E. ERNST :

- M. Inayama et al.

Chylothorax caused by acupuncture. Intern. Med. 50 (2011) 2375-2377

\section{Achtung:}

\section{Hier muss der Dummy durch eine Anzeige ersetzt werden !!}

